\title{
O Docente Formador na coordenação do PIBID: os desafios para a condução da Iniciação à Docência
}

\section{The Teacher Training in the Coordination of PIBID: the challenges for conducting the Initiation to Teaching}

\author{
Shirléia dos Santos Peixoto ${ }^{1 *}$, Fernando Paulo de Lima ${ }^{1}$, José Jairo Vieira ${ }^{2}$
}

\begin{abstract}
RESUMO
Neste trabalho objetivamos analisar as competências necessárias para a condução da iniciação à docência a partir da coordenação do docente formador diante do PIBID, no contexto neoliberal das atribuições e desafios contemporâneos nas instituições de ensino superior (IES). A partir de uma análise da produção teórica, podemos considerar que é necessário que os formadores tenham domínio de saberes e competências específicas que lhe permitam uma análise de conjuntura ao observar o seu ser-fazer pedagógico, a fim de desempenhar sua principal função: formar seres humanos para educar outros seres humanos. Para tanto, é imprescindível que humanize o seu olhar e a sua prática pedagógica. Por fim, concluímos que o PIBID pode ser uma ação que contribui para o incentivo da escola como lócus de formação inicial e continuada de professores e cabe a futuros estudos avaliar o programa a partir do olhar dos docentes formadores, a fim de ampliar o debate.
\end{abstract}

Palavras-chave: Ensino Superior; Política Educacional; PIBID; Formação Docente;

\begin{abstract}
In this work we aim to analyze the necessary competences for conducting the initiation to teaching from the coordination of the teacher trainer before the PIBID, in the neoliberal context of contemporary attributions and challenges in higher education institutions (IES). From an analysis of the theoretical production, we can consider that it is necessary for the trainers to have mastery of specific knowledge and skills that allow them to analyze the conjuncture when observing their pedagogical being-doing, in order to perform their main function: to form beings humans to educate other human beings. Therefore, it is essential to humanize your look and your pedagogical practice. Finally, we conclude that PIBID can be an action that contributes to encouraging the school as a locus of initial and continuing teacher training and it is up to future studies to evaluate the program from the point of view of the training teachers, in order to broaden the debate.
\end{abstract}

Keywords: Higher Education; Educational Policy; PIBID; teacher training;

\section{INTRODUÇÃO}

A formação inicial de futuros professores, muitas vezes, é questionada quanto a sua qualidade, uma vez que a literatura científica aponta várias críticas concernentes aos

\footnotetext{
${ }^{1}$ Secretaria Municipal de Educação do Rio de Janeiro / Universidade Federal do Rio de Janeiro.

*E-mail: diversidade.desigualdade.educa@gmail.com

${ }^{2}$ Universidade Federal do Rio de Janeiro.
} 
cursos de licenciatura, dentre as quais destacamos o distanciamento entre a teoria e a prática, ou ainda, entre a universidade e a escola de educação básica. No bojo dessa questão, encontra-se a ineficiência dos momentos da formação em que os licenciandos têm a oportunidade de conhecer a realidade escolar, no caso, as práticas de ensino e os estágios supervisionados. Dessa forma, os cursos de licenciatura têm enfrentado o desafio de dialogar com a complexidade da educação brasileira, no contexto da crise das profissões, onde a provisoriedade do conhecimento e a precarização das condições de trabalho tornam a atuação profissional ainda mais conflituosa.

Nesse contexto, iniciativas do governo federal como o Programa Institucional de Bolsas de Iniciação à Docência (PIBID) procura ampliar a procura pelos Cursos de Licenciatura e incentivar a coparticipação entre universidade e escola de educação básica, diminuindo a distância entre teoria e prática na formação inicial e continuada de professores. Para incentivar essa prática o governo federal concede bolsas aos membros envolvidos nesse projeto: licenciandos, professore supervisores da escola e professores formadores que atuam em cursos de licenciatura. Os objetivos dessa ação formativa colaborativa é oportunizar a troca de conhecimentos e a construção da profissionalidade dos respectivos membros envolvidos.

Neste trabalho temos como foco específico de nossa atenção, a atuação do docente formador na condução do PIBID. Para tanto, objetivamos: delimitar os desafios da formação inicial na contemporaneidade; levantar as lacunas e possibilidades das condições de trabalho e formação do docente formador; compreender a possibilidade da parceria entre os envolvidos na condução do PIBID e, por fim, delimitar as competências necessárias para o trabalho do professor formador diante da coordenação do PIBID.

A partir desses elementos, o objetivo do presente estudo é discutir quais as competências necessárias para a condução da iniciação à docência a partir da coordenação do docente formador diante do PIBID, no contexto neoliberal das atribuições e desafios contemporâneos nas instituições de ensino superior (IES). Procuraremos responder: os professores formadores estão preparados para mediar os alunos das licenciaturas durante sua iniciação à docência? Quais competências necessárias? Iniciativas como o PIBID pode contribuir para a formação continuada dos docentes formadores?

\section{DESAFIOS DA FORMAÇÃO INICIAL: A BUSCA DA SUPERAÇÃO DA DICOTOMIA TEORIA X PRÁTICA}


As pesquisas sobre formação de professores cresceram muito nos últimos anos. No Estado da Arte realizado por Gatti, Barreto e André (2011) acerca do mapeamento da produção acadêmica dos pós-graduandos na área de educação, mostra que na década de 1990, o volume proporcional de dissertações e teses da área de educação que tinham como foco a formação de professores girava em torno de 7\%; já no início dos anos de 2000, esse percentual cresce consideravelmente, atingindo 22\%, em 2007. Dessa produção, a maioria dos trabalhos se refere à formação inicial.

O interesse pela investigação da formação inicial, segundo Cunha (2010) parte dos esforços para delimitar os desafios que cercam a formação inicial, torna-se necessário compreender, dentre outras questões, a permanente tensão entre teoria e prática, ensino e pesquisa, universidade e escola.

Antes de seguirmos a discussão acerca dos impasses e possibilidades que a formação inicial tem enfrentado na contemporaneidade, precisamos apresentar o conceito que defendemos de formação de professores. Partindo da definição de Garcia (1999):

\begin{abstract}
A formação de professores é a área de conhecimento, investigação e de propostas teóricas e práticas que, no âmbito da Didáctica e da Organização Escolar, estuda os processos através dos quais os professores - em formação ou em exercício - se implicam individualmente ou em equipa, em experiências de aprendizagem através das quais adquirem ou melhoram seus conhecimentos, competências e disposições,e que lhes permite intervir profissionalmente no desenvolvimento do seu ensino, do currículo e da escola, com o objectivo de melhorar a qualidade da educação que os alunos recebem (p.26).
\end{abstract}

Identifica-se, historicamente, que a formação e a prática docente tem sido associada à questão missionária, como se o "ser professor" estivesse munido de uma vocação inata, ou que cabe ao professor, individualmente, a responsabilidade de modificar o mundo, sem as necessárias condições para o exercício do seu trabalho e/ou à mercê das dificuldades do ofício.

Para Nóvoa (1995, p.21): “Uns e outros tem do ensino a visão de uma actividade que se realiza com naturalidade, isto é, sem necessidade de qualquer formação específica, na sequência da detenção de um determinado corpo de conhecimentos científicos".

Dentre as concepções que questionam como deve se dar a formação inicial de professores, levando em consideração sua especificidade, a preocupação principal é como formar o professor para enfrentar o universo escolar, preparando-o para seus desafios.

Segundo Nóvoa: 
A formação de professores tem ignorado, sistematicamente, $\mathrm{o}$ desenvolvimento pessoal, confundindo "formar" em "formar-se", não compreendendo que a lógica da actividade educativa nem sempre coincide com as dinâmicas próprias da formação. Mas também não tem valorizado uma articulação entre a formação e os projectos das escolas, consideradas como organizações dotadas de margens de autonomia e de decisão de dia para dia mais importantes. Estes dois "esquecimentos" inviabilizam que a formação tenha como eixo de referência o desenvolvimento profissional dos professores, na dupla perspectiva do professor individual e do coletivo docente. (1995, p.24).

$\mathrm{O}$ autor aponta a negligência entre a formação técnica que distancia os métodos da aprendidos durante a formação e a realidade encontrada no espaço escolar. Assim, valorizando a experiência e a reflexão na experiência, Schön (1995) apoia uma formação profissional baseada numa epistemologia da prática reflexiva, onde o currículo de formação de professores seja capaz de desenvolver a reflexão, desde o início do curso. $\mathrm{O}$ autor ainda apresenta a dificuldade em se formar o professor dentro de um practicum reflexivo a partir da própria epistemologia da Universidade, e do currículo profissional normativo:

Primeiro ensinam-se os princípios científicos relevantes, depois a aplicação desses princípios e, por último, tem-se um practium cujo objectivo é aplicar à prática quotidiana os princípios da ciência aplicada. Mas, de facto, se o practium quiser ter alguma utilidade, envolverá sempre outros conhecimentos diferentes do saber escolar. (Schön, 1995, p.91).

Enquanto algumas linhas de formação de professores defendem a prática como o principal componente curricular desde o início da formação inicial, outros autores argumentam a favor do componente teórico como forma de tornar coletiva a discussão acerca dos dilemas na prática docente. Para Pimenta (2005, p.23), a teoria tem importância fundamental na formação dos docentes, pois dota os sujeitos de variados pontos de vista para uma ação contextualizada, oferecendo perspectivas de análise para que os professores compreendam os conceitos históricos, sociais, culturais, organizacionais e de si próprios como profissionais.

Segundo Libâneo (1998, p.41), “[...] é importante a incorporação de teorias e sua produção para a melhoria das práticas de ensino e dos resultados”. Considerando a prática em sala de aula, Pimenta (2005, p.25), argumenta que: "Ao colocar o papel da teoria como possibilidade para a superação do praticismo, ou seja, da crítica coletiva e ampliada para além dos contextos de aula e da instituição escolar, incluindo as esferas sociais mais amplas e ao evidenciar o significado político da atividade docente". 
Contreras (2002) considera que existem vários fatores que influenciam a prática e a formação do professor. Para o autor, compreender esses processos que afetam diretamente a autonomia do professor significa considera-lo como um "intelectual crítico":

[...] um profissional que participa ativamente do esforço para descobrir o oculto, para desentranhar a origem histórica e social do que se apresenta como "natural", para conseguir captar e mostrar os processos pelos quais a prática de ensino fica presa em pretensões, relações e experiências de duvidoso valor educativo. (Contreras, 2002, p.185).

Assim sendo, não podemos desconsiderar a pluralidade social e tampouco dos saberes e das desigualdades. Dessa forma, a prática docente bem como sua formação, não pode se reduzir às técnicas, visto a especificidade do ofício do magistério. E ainda, segundo Pimenta:

A compreensão dos fatores sociais e institucionais que condicionam a prática educativa e a emancipação das formas de dominação que afetam nosso pensamento e nossa ação não são espontâneas e nem se produzem naturalmente. São processos contínuos de descoberta, de transformação das diferenças de nossas práticas cotidianas. (2005, p.28).

Esse movimento que coloca a atuação docente em direção a uma perspectiva emancipatória e de diminuição das desigualdades sociais através da escolarização plural, a qual, geralmente, é negligenciada pela exacerbação da técnica em relação à reflexão pedagógica. Essa exacerbação da técnica se faz presente, por exemplo, no discurso sobre as competências, que nada mais significa do que uma tecnicização do trabalho do professor e de sua formação. (PIMENTA, 2005). Assim, a análise das contradições presentes na apropriação histórica e concreta, evidenciadas na pesquisa teórica e empírica empreendida, subsidia a proposta de superar-se a identidade necessária dos professores de reflexivos para a de intelectuais críticos e reflexivos. (PIMENTA, 2005).

No caso dos cursos de licenciatura, a dualidade "teoria x prática" tem sido apontada como desafio na atualidade principalmente pelo desinteresse pela docência e na desvalorização da escola pública. A partir desse quadro, políticas educacionais de formação e incentivo à docência procuram juntamente com o estágio supervisionado e as práticas de ensino, reduzir o fosso entre a universidade e a escola. Assim sendo, faz-se necessário refletir acerca das competências necessárias para conduzir a formação de novos professores, especificamente ao imergir na realidade das escolas, além de realizar uma leitura do contexto atual do trabalho do docente formador diante das diferentes demandas que lhes são apresentadas e de sua formação. 


\section{O TRABALHO E A FORMAÇÃO DO DOCENTE FORMADOR NA CONTEMPORANEIDADE}

Os impactos do neoliberalismo nas condições de trabalho dos docentes universitários vêm sendo investigados por vários autores. (PIMENTA e ANASTASIOU, 2002; MOROSINI, 2001; ISAIA et. al., 2013; CUNHA 2010; FAGUNDES, 2013; FERENC e MIZUKAMI, 2008; MAUÉS, 2008). Desde o processo de socialização dos professores iniciantes, a falta de acompanhamento e o isolamento são questões preponderantes no desenvolvimento da identidade profissional, seguidos da ênfase na pesquisa, características que compõe em parte, o cenário da docência no ensino superior. Externamente, as políticas de avaliação institucional e os índices cobrados a partir da produção acadêmica, direcionam suas práticas e esforços para a pesquisa, negligenciando o ensino e o fazer pedagógico.

André et. al. (2013, p.123) apontam que no Brasil, as reformas educacionais implantadas nos últimos dez anos atribuem ao professor um papel central na melhoria do processo educativo. A formação do docente tornou-se, então, um dos temas mais importantes na agenda das reformas. Espera-se muito dos cursos de formação inicial e, consequentemente, dos professores formadores.

Vaillant (2003) define o professor formador como o profissional que se dedica à formação de mestres e professores, e realiza diversas tarefas, não apenas na formação inicial e permanente de docentes, como também em planos de inovação, assessoria, planejamento e execução de projetos nas áreas de educação, formal e informal. São responsáveis em ler o contexto cultural de seus estudantes, muitos deles com lacunas na preparação científica desejada. (CUNHA, 2010); responsáveis em organizar e dirigir situações de aprendizagem. (PERRENOUD, 2000); e que permitam o desenvolvimento das capacidades de aprendizagem da relação, da convivência, da cultura do contexto e de interação de cada pessoa com o resto do grupo, com seus semelhantes e com a comunidade que envolve a educação. (IMBERNÓN, 2006).

Nesse contexto de exigências e expectativas em relação ao trabalho do professor formador vem ocorrendo um aumento vertiginoso do número de cursos de licenciatura e o consequente e significativo crescimento do número de alunos. Porém as exigências legais, somadas às circunstâncias atuais do crescimento dos cursos de licenciatura, não têm alterado o contexto de valorização dos professores que neles atuam, e a lógica de 
estruturação desses cursos traz preocupações em relação à qualidade da formação que propiciam.

A intensificação do trabalho docente e a ênfase dada à pesquisa têm colocado as atividades vinculadas ao ensino em plano secundário, sendo que a cultura institucional na contemporaneidade é marcada pela avaliação do professor a partir dos produtos publicados. Além da cultura institucional das universidades de privilegiar a pesquisa em detrimento do ensino, outra questão que merece ser discutida é a formação dos docentes formadores e o lugar dos saberes pedagógicos nesse processo.

Gonçalves (2000) ao analisar a formação de professores formadores de um curso de Matemática, constatou que a formação acadêmica dos formadores foi predominantemente técnico-formal, com ênfase quase que exclusiva na formação matemática; a formação geral e a formação pedagógica dos formadores, além de reduzidas, aconteceram dissociadas da formação técnico-científica e distanciadas das práticas profissionais do professor de Matemática; os saberes relativos à como formar professores de Matemática foram adquiridos na prática ou na experiência anterior como professores da Educação Básica.

Esse perfil técnico-científico da formação do professor formador não é específico dos cursos de licenciatura em Matemática, mas aparece como requisito central na formação e atuação dos docentes universitários da maioria dos campos disciplinares, que tem ocasionado dificuldades por parte dos formadores em lidarem com as demandas de um "licenciando real" e de uma "escola real". Somando-se aos desafios da licenciatura, André et. al. (2013) apontam que no contexto de mudanças e novas demandas para o trabalho do formador: alunos cada vez mais utilitaristas e pragmáticos, indisciplinados, desmotivados, alunos que apresentam defasagens da educação básica (como a leitura e a escrita, por exemplo), e com pouco interesse pela profissão docente.

Atrelado a esses fatores está a precarização da escola pública, e o desprestígio da profissão docente. Torna-se tarefa para o professor formador, juntamente com o licenciando, analisar criticamente a situação observada nas escolas, ponderando todas as variáveis que concorrem para que se consiga separar a parte que compete ao docente e a que é de responsabilidade de outras instâncias (ANDRÉ et. al., 2013).

A realidade da escola básica brasileira, em especial da escola pública, assusta os estudantes e leva muitos deles a pensar em desistir dos cursos de licenciatura, em mudar de profissão. Outro desafio com que os professores formadores se defrontam diz respeito 
à tarefa de formar profissionalmente o aluno, "promovendo condições para o aprendizado da docência e para a apropriação do saber profissional que é específico e indispensável ao desenvolvimento dessa atividade" (ANDRÉ et. al., 2013). A sobrecarga, a exaustão emocional, o estado permanente de cansaço e até depressão tem sido algumas das consequências negativas do trabalho docente vivenciadas pelos professores.

Segundo Passos (2007), necessita-se considerar que o trabalho do professor se tornou mais complexo em função das modificações de seus saberes profissionais e de suas condições de trabalho, portanto, tem exigido maiores níveis de profissionalização. Os professores alegam que tem sido impraticável realizar essa tarefa sem reorganizar o ensino e adequar o trabalho pedagógico ao perfil do aluno e às suas necessidades. No entanto, André et. al. (2013) defendem que iniciativas se limitam ao âmbito individual, enquanto deveria fazer parte do projeto político-pedagógico e ser assumida pelo coletivo institucional.

\section{O PROGRAMA INSTITUCIONAL DE BOLSAS DE INICIAÇÃO À DOCÊNCIA (PIBID) E A ESCOLA COMO “TERCEIRO ESPAÇO” DE FORMAÇÃO}

O Programa Institucional de Bolsas de Iniciação à Docência $\left(\mathrm{PIBID}^{3}\right)$ foi criado em 2007 com o objetivo prioritário de formar professores principalmente para atuarem no ensino médio nas áreas de Química, Biologia e Matemática. Como consequência dos seus primeiros resultados positivos, em 2009, o Programa passou a atender todas as licenciaturas. O Programa acontece por meio de convênios entre a Coordenação de Aperfeiçoamento de Pessoal de Nível Superior (CAPES), as Instituições de Ensino Superior (IES) e as escolas públicas de Educação Básica. Assim, o Programa conta com a colaboração de licenciandos, professores supervisores da Educação Básica (atuantes na escola) e, docentes das IES que, no caso, coordenam e mediam a relação entre os estudantes, a escola e o supervisor.

Outros objetivos do PIBID são: incentivar a formação de docentes em nível superior para a educação básica; contribuir para a valorização do magistério; elevar a qualidade da formação inicial de professores nos cursos de licenciatura, promovendo a

\footnotetext{
3 É importante ressaltar que as portarias que regulamentaram o PIBID foram substituídas pelo decreto $\mathrm{n}^{\circ}$. 7.219/2010, o qual institucionalizou o Programa, indicando, assim, a preocupação com a sua consolidação e continuidade, o que sinaliza para a configuração do PIBID como uma política de Estado.
} 
integração entre educação superior e educação básica; inserir os licenciandos no cotidiano de escolas da rede pública de educação; incentivar escolas públicas de educação básica, mobilizando seus professores como conformadores dos futuros docentes e tornando-as protagonistas nos processos de formação inicial para o magistério; e contribuir para a articulação entre teoria e prática necessárias à formação dos docentes, elevando a qualidade das ações acadêmicas nos cursos de licenciatura.

Akkari (2011) aponta algumas tendências internacionais na formação de professores, sendo marcadas pela universitarização ou terceirização da formação, com o objetivo de propiciar aos professores uma formação mais científica e menos baseada em "receitas". Entretanto, essa formação tem sido influenciada pelo pouco status ocupado $p$ elas licenciaturas nas universidades, e sua distância significativa com a realidade escolar. Nesse sentido, um dos questionamentos apontados é se "esta universitarização agrava o fosso entre a teoria (formação inicial) e a prática (ensino na escola)"? (AKKARI, 2011, p. 111)

$\mathrm{Na}$ configuração das propostas externas que buscam orientar as diretrizes para a formação de professores no Brasil, Maués e Camargo (2014) apontam para o fato de que:

\begin{abstract}
São relevantes as orientações advindas de organismos internacionais, como é o caso da Oficina Regional de Educação para a América Latina e o Caribe (OREALC) e da Organização das Nações Unidas para a Educação, a Ciência e a Cultura (UNESCO), e que se refletem nas políticas de valorização do docente no Brasil nos últimos dez anos, inclusive aquelas que se voltam para a formação inicial e sua expansão em nível superior. É preciso reformar a escola e formar os professores para atender a tais demandas. (p.79).
\end{abstract}

Uma das principais críticas apresentadas no relatório é a de que a formação dos docentes da educação básica é muito teórica, desvinculada da prática efetiva e distanciada das escolas para as quais ela prepara. Nesse aspecto, o PIBID é criado no Brasil com a premissa de ampliar a procura pelas licenciaturas e diminuir a distancia entre a teoria e a prática (universidade/realidade escolar), que não vem formando os jovens para a "sociedade do conhecimento" e as novas necessidades educativas inerentes a contemporaneidade. O estudo feito pela OREALC/UNESCO apoiou-se no tripé formação inicial, formação continuada e carreira, sendo analisados os "nós críticos" desses eixos e apresentadas propostas de resolução.

Assim, para a formação inicial, Maués e Camargo (2014) apontam os seguintes 
pontos que compõem o documento:

Baixo nível de formação das pessoas que procuram os cursos de licenciatura; os programas dos cursos de formação têm baixa qualidade; uma formação universalista, sem dar ênfase ao fato de que esses professores precisam trabalhar com alunos oriundos de famílias de baixa renda; falta de uma maior regulação dos órgãos competentes. (p.80)

E ainda, localizam o PIBID no movimento de construção de uma legislação que atenda as diretrizes estipulada pelos organismos internacionais para a formação docente:

Em abril de 2013, uma alteração vai se efetivar no artigo 62 da LDB/96, que tem mais parágrafos acrescidos, dessa vez a ênfase é dada à responsabilidade da União e dos entes federados que devem adotar mecanismos que facilitem não apenas o acesso e a permanência nos cursos de formação em nível superior, como também deverão incentivar "profissionais do magistério para atuar na educação básica pública mediante programa institucional de bolsa de iniciação à docência destinado a estudantes matriculados em cursos de licenciatura, de graduação plena." (MAUÉS e CAMARGO, 2014, p.83).

Imbernón (2006) afirma que a estrutura da formação inicial deve possibilitar uma análise global das situações educativas que, devido à carência ou à insuficiência da prática real, se limitam predominantemente a simulações dessas situações. Geralmente essas iniciativas esbarram na proposta de superar as críticas relativas à sua organização curricular, notadamente as relativas à falta de articulação teoria e prática e entre os campos disciplinares, ou seja, "a não consideração da lógica profissional, e em que os campos disciplinares se estruturaram à parte e desvinculados do próprio ensino." (PASSOS, 2007).

Buscando refletir sobre a implementação da escola como lócus privilegiado para a formação inicial de professores de maneira significativa a partir de iniciativas como o PIBID, utilizaremos o conceito de "terceiro espaço" apresentado por Zeichner (2010). Em sua obra, o autor busca apresentar e discutir uma série de esforços atuais, nos Estados Unidos, para diminuir as lacunas entre a formação docente que acontece na universidade e aquela que se dá na escola, assim como as lacunas entre essas duas e as comunidades mais amplas nas quais as escolas, as faculdades e as universidades se inserem. Para tanto, o autor defende que a formação dos terceiros espaços,

[...] envolvem uma rejeição das binaridades tais como entre $o$ conhecimento prático profissional e o conhecimento acadêmico, entre a teoria e a prática, assim como envolve a integração, de novas 
maneiras, do que comumente é visto como discursos concorrentes em que uma perspectiva do isso ou aquilo é transformada num ponto de vista do tanto isso, quanto aquilo. (ZEICHNER, 2010, p. 486).

$\mathrm{O}$ conceito trazido pelo autor diz respeito à criação de espaços híbridos nos programas de formação inicial de professores que reúnem professores da Educação Básica e do Ensino Superior, que no caso do PIBID, torna-se efetivo na atuação do coordenador do subprojeto e o professor supervisor da escola, trabalhando coletivamente na junção entre o conhecimento prático profissional e acadêmico em novas formas para aprimorar a aprendizagem dos futuros professores. Dessa maneira, "os terceiros espaços reúnem o conhecimento prático ao acadêmico de modos menos hierárquicos, tendo em vista a criação de novas oportunidades de aprendizagem para professores em formação." (ZEICHNER, 2010, p. 487).

$\mathrm{Na}$ busca de fortalecer a parceria entre a universidade e a escola, Zeichner sugere uma reformulação da conexão entre as disciplinas da formação inicial de professores nas faculdades e nas universidades e as escolas da rede e as comunidades para as quais esses alunos estão sendo preparados. É um sinal otimista de que o tradicional modelo distanciado e desconectado da formação inicial baseada na universidade está em pleno esfacelamento. Todavia cabe ressaltar que essas experiências devem ser balizadas e fundamentadas, sobretudo, a partir da percepção do professor formador de quais os limites e potencialidades para a condução das experiências dos bolsistas do PIBID.

Uma alternativa para os professores universitários formadores de professores, "que adotam os modelos das práticas dos professores da Educação Básica, é produzir modelos a partir de suas próprias experiências e práticas no ensino fundamental e médio a fim de utilizá-las na prática do ensino superior" (ZEICHNER, 2010, p. 489). Quais as competências necessárias para tornar o programa um terceiro espaço de formação?

\section{O PROFESSOR FORMADOR E AS COMPETÊNCIAS NECESSÁRIAS PARA A CONDUÇÃO DO PIBID: INÍCIO AO DEBATE}

Para Perrenoud (2000), competência é a faculdade de mobilizar um conjunto de recursos cognitivos (saberes, capacidades, informações etc.) para solucionar com pertinência e eficácia uma série de situações ligadas a contextos culturais, profissionais e condições sociais. Assim, o docente formador necessita desenvolver competências que o permita estruturar e conduzir a formação de novos professores. E nesse processo está a formação do próprio professor formador, suas experiências e a relevância atribuída ao 
ensino durante sua trajetória. Ferenc e Mizukami (2008) apontam que a atividade de ensino para o docente universitário deve ser compreendida como objeto de pesquisa e de investimento, e não apenas como lugar de reprodução de conhecimento.

Todavia, em levantamento realizado por Vaillant (2003), a partir do PREAL ${ }^{4}$, aponta para o fato que no geral, poucas são as horas que os professores formadores dedicam à sua formação e à reflexão coletiva nos estabelecimentos de ensino e acabam reproduzindo em seu exercício profissional, o que aprenderam com seus professores quando eram alunos. Por isto, é imprescindível refletir sobre qual é o perfil de docente que se deseja promover para, então, avançar na questão do como fazê-lo no caso daqueles que já estão em exercício. “Os docentes latino-americanos carecem, muitas vezes, de conhecimentos e habilidades pedagógicas para desenvolver as atividades e produzir os conhecimentos esperados." (VAILLANT, 2003).

Desde o início de carreira, os docentes universitários sofrem com a falta de interação ou acompanhamento, o chamado "choque de realidade", onde encontram salas de aulas superlotadas, excesso de carga horária docente, falta de material e equipamentos, infraestruturas precárias, burocratização das tarefas, alunos desinteressados e indisciplinados, violência, etc. (TARDIF, 2002). Ainda assim, estão incumbidos da tarefa de desenvolver nos futuros docentes competências para participação na vida pública, para um desenvolvimento produtivo na vida moderna e na construção das bases para a educação permanente.

Dessa maneira, o contexto atual requer um professor universitário competente para atuar nos cursos de licenciatura. Pensando no PIBID, quais competências seriam necessárias para a condução do programa? A partir da leitura dos documentos que regulamentam o PIBID, temos as seguintes exigências para a seleção dos docentes coordenadores das licenciaturas:

I - possuir formação - graduação ou pós-graduação - na área do subprojeto; [...] III - ser docente e estar em efetivo exercício das atividades do magistério no ensino superior; IV - possuir experiência mínima de 3 (três) anos como docente do ensino superior; V - ministrar disciplina em curso de licenciatura da IES na área do subprojeto; VI possuir experiência na formação de professores ou na execução de projetos de ensino; VII - possuir competência técnica compatível com

\footnotetext{
${ }^{4}$ Programa de Promoção da Reforma Educativa na América Latina e Caribe.
} 
a função de coordenador de projeto, bem como disponibilidade para dedicação ao programa. (BRASIL, 2013).

A exigência de que o coordenador esteja vinculado e lecionando em cursos de licenciatura, demonstra a preocupação com a identificação do docente formador com a Educação Básica. Essa familiaridade com a licenciatura, e por conseguinte, com a realidade das escolas de Educação Básica exigida nos documentos que regulamentam o programa corrobora com as indicações já discutidas por Zeichner (2010), que se trata da criação do "terceiro espaço" de formação docente. Por isso a importância dessa vivência anterior do coordenador das ações formativas, rompendo com a visão da racionalidade técnica durante a estruturação do programa. Nos Estados Unidos é comum alguns formadores de professores, aproveitarem o espaço da escola e estrategicamente conectarem suas disciplinas de metodologia, que lecionam no contexto da escola, com as práticas e o conhecimento especializado dos professores nessas escolas.

Todavia, Vaillant (2003) aponta que os formadores não têm, em geral, conexão com as escolas, deixando, por isto, de ficarem atualizados sobre as inovações e práticas dos centros educativos. É preciso, portanto, repensar a formação de formadores, tomando a escola com pano de fundo, de modo a contribuir para superar a tradicional dissociação entre formação e prática que tem caracterizado o aprender a ensinar. Assim, ao considerar o PIBID como programa mediador entre a formação inicial dos licenciando e a formação continuada dos professores da escola, podemos considerar também a formação continuada dos docentes formadores a partir de sua (re)aproximação (em muitos casos) com a realidade escolar.

Segundo Vaillant (2003), “as aulas nas universidades são dadas por professores universitários que desconhecem o trabalho em aula", e essa questão atinge o trabalho pedagógico e a profissionalidade do professor formador. Entendemos por profissionalidade, um conjunto de capacidades e saberes desenvolvidos no desempenho de suas funções num determinado momento histórico. (TEIXEIRA, 2012, p.4).

Portanto, o conceito de profissionalidade deve ser analisado dentro de um contexto histórico, a partir das relações sociais. Dessa forma, diferentes contextos geram diferentes profissionalidades. Teixeira (2012) aponta quatro contextos distintos, a saber: o contexto pedagógico, o contexto profissional, o contexto sociocultural, e por fim, o contexto político. Por isso, desconhecer a realidade da escola compromete a tarefa de formar novos professores, assim, os formadores de docentes devem interessar-se pelas práticas como componentes formativos. Ainda que as práticas de ensino continuem sendo o elemento 
mais valorizado pelos docentes, tanto em formação, como em exercício, às vezes esperase demasiado delas, mantendo expectativas pouco realistas a seu respeito. (VAILLANT, 2003).

Imbernón (2006) defende que:

\begin{abstract}
As práticas nas instituições educativas devem favorecer uma visão integral dessas relações e devem levar necessariamente a analisar estreita relação dialética entre teoria e prática educativa. As práticas devem ser o eixo central sobre o qual gire a formação do conhecimento profissional básico do professor. As práticas devem servir de estímulo às propostas teórico-práticas formais, de maneira a permitir que os alunos interpretem, reinterpretem e sistematizem sua experiência passada e presente, tanto intuitiva como empírica. (p.64).
\end{abstract}

Ainda sobre as exigências trazidas no edital do PIBID acerca das competências necessárias aos coordenadores, no item "possuir competência técnica compatível com a função de coordenador de projeto" podemos questionar: de quê competência técnica o documento trata? Ou ainda, a competência técnica isoladamente corresponde às necessidades de coordenar o programa? Quais competências são necessárias para a condução da formação de professores a partir do PIBID? Buscando responder essas questões, discutiremos as cinco competências apresentadas por Vaillant (2003):

a) Didático-pedagógica: refere-se aos critérios de seleção entre uma série de estratégias conhecidas para intervir intencionalmente, promovendo as aprendizagens dos alunos - a preocupação em estruturar o subprojeto de forma a contemplar todas as dimensões que compreendem a realidade escolar, permitindo a imersão no cotidiano da educação brasileira;

b) Político-institucional: capacidade dos docentes em articular a macropolítica referida ao conjunto do sistema educativo com a micropolítica do que é necessário programar, instituir e avaliar nas instituições - despertar no licenciando a consciência política da docência, permitindo enxergar-se como futuros professores, conhecendo o funcionamento da escola a partir da legislação, do papel da escola na sociedade contemporânea;

c) Produtiva: permite aos docentes compreender o mundo em que vivem e viverão, e intervir como cidadãos produtivos - desencadear no futuro professor a utopia da transformação da educação, pela busca de uma prática pedagógica coerente e ética;

d) Interativa: conhecer e compreender a cultura das crianças e dos jovens, as peculiaridades das comunidades, as formas de funcionamento da sociedade civil e sua 
relação com o Estado, de exercer a tolerância e a cooperação entre diferentes - produzir o sentimento de empatia no processo ensino-aprendizagem dos futuros professores, a partir de situações concretas e respeitando as diferenças no aprender e no ensinar;

e) Especificadora: refere-se a que hoje parece conveniente que, nas escolas primárias ou de educação genérica, haja professores que possam especificar competências por meio de saberes disciplinares mais sólidos e que, nas escolas secundárias, possam eles especificar as outras competências através de conhecimentos mais profundos sobre as instituições e sobre os que a elas estão submetidos.

Assim, o desafio dos docentes formadores é conduzir o processo de iniciação à docência, considerando o contexto no qual está inserido, mobilizando suas competências em um processo de auto-formação. Vaillant (2003) sugere que a chave seria conseguir que as intervenções dos formadores em programas de formação inicial ou contínua de docentes não fiquem apenas no campo retórico, afetando efetivamente o que ocorre nas aulas e o que aprendem os alunos dos centros educativos.

\section{CONSIDERAÇÕES FINAIS}

O docente formador ocupa uma posição de destaque na formação de professores. Primeiramente, pelo fato de ser o responsável em conduzir, estruturar, avaliar, gerenciar (entre outras atribuições) os cursos de formação inicial, e os programas de iniciação à docência como o PIBID. Todavia, esse processo vem sendo comprometido em função da intensificação e das novas demandas do trabalho docente, sejam elas de ordem institucional (produtividade científica e atividades administrativas), seja pelo perfil dos ingressos nos cursos de licenciatura (estudantes oriundos de camada popular com déficit de conhecimentos da Educação Básica), seja pelo próprio déficit formativo dos docentes formadores para exercerem o magistério superior (carência da formação pedagógica, falta de experiência na Educação Básica, isolamento em seu trabalho).

A distância que existe entre a formação inicial ofertada nos cursos de licenciatura e a realidade das escolas de educação básica, a ênfase dada pelas avaliações institucionais nas universidades à atividade de pesquisa realizada pelos professores e a deficiência na própria formação profissional dos docentes formadores têm dificultado a mobilização do interesse dos licenciandos de se tornarem professores.

Nesse sentido, o diálogo entre a universidade e as escolas de educação básica apresenta-se como um dos caminhos possíveis para reduzir as lacunas dos cursos de 
licenciatura. Construir o conhecimento a partir de situações concretas, compreender a escola como lócus de formação inicial e continuada e buscar desenvolver as competências que permitam a condução dos cursos de licenciatura de forma humana e compromissada com a escola pública, é responsabilidade das políticas e ações voltadas à formação docente. Programas como o PIBID quando estruturados de maneira coerente, são essenciais para a diminuição do fosso entre a escola e a universidade.

Ressignificar a teoria a partir da prática é potencializar a formação de professores críticos e reflexivos. Portanto, conceber o "terceiro espaço" como lócus de formação se torna fundamental para a condução das experiências formativas e para o desenvolvimento da identidade profissional docente, tanto para os licenciandos quanto para o professor universitário e o professor da escola. Porém, essa conduta parte da familiaridade por parte do professor coordenador do PIBID com a realidade da escola pública, o que na maioria dos casos, não acontece.

Respondendo às questões que ancoraram este estudo, e a partir da fala dos autores apresentados, os professores formadores estão preparados para coordenar o PIBID e mediar os estudantes de cursos de licenciatura participantes desse projeto, desde que reconheçam na escola, a finalidade do seu trabalho educativo. Nesse sentido, é necessário que os formadores tenham domínio de saberes e competências específicas que lhe permitam uma análise de conjuntura ao observar o seu ser-fazer pedagógico, a fim de desempenhar sua principal função: formar seres humanos para educar outros seres humanos. Para tanto, é imprescindível que humanize o seu olhar e a sua prática pedagógica. Por fim, concluímos que o PIBID pode ser uma ação que contribui para o incentivo da escola como lócus de formação inicial e continuada de professores e cabe a futuros estudos avaliar o programa a partir do olhar dos docentes formadores, a fim de ampliar o debate.

\section{REFERÊNCIAS}

AKKARI, A. Internacionalização das políticas educacionais: transformações e desafios. Petrópolis, Rio de Janeiro: Vozes, 2011.

ANDRÉ, M. E. D. A. et al. O trabalho docente do professor formador no contexto atual das reformas e das mudanças no mundo contemporâneo. Revista Brasileira de Estudos Pedagógicos, Brasília, DF, v. 91, n. 227, p. 122-143, jan./abr. 2010.

BRASIL. Ministério da Educação. Decreto n. 7.219. Dispõe sobre o Programa Institucional de Bolsa de Iniciação a Docência - PIBID, 24 de julho de 2010. 
Ministério da Educação. Portaria $n^{\circ}$ 096. Dispõe sobre o novo regulamento do Programa Institucional de Bolsa de Iniciação a Docência - PIBID, 18 de julho de 2013.

CONTRERAS, J. A autonomia de professores. São Paulo: Cortez, 2002.

CUNHA, M. I. da. O campo da iniciação da docência universitária como um desafio. In: REUNIÃO ANUAL DA ANPED, 33. 2010, Caxambu. Educação no Brasil: o balanço de uma década. Gt 04 Didática. Caxambu, 2010.

FAGUNDES, M. C. V.; BROILO, C. L.; FORSTER, M. M. dos S. É possível construir a docência universitária? Apontamos caminhos. In: REUNIÃO ANUAL DA ANPED, 31. 2008, Caxambu. Constituição Brasileira, Direitos Humanos e Educação. Gt 08 Formação de professores. Caxambu, 2008.

FERENC, A. V. F.; MIZUKAMI, M. das G. N. Trabalho docente e condições de desenvolvimento profissional de docentes universitários. In: Universidade e sociedade. Produção versus produtivismo e precarização do trabalho. Ano XVII $-\mathrm{n}^{\circ} 41-$ jan, 2008. p.117-131.

GARCÍA, C. M. Formação de professores: para uma mudança educativa. Porto: Porto Editora Ltda., 1999.

GATTI, B. A.; BARRETTO, E. S. S.; ANDRÉ, M. E. D. A. (Orgs.) Políticas Docentes no Brasil: um estado da arte. Brasília: UNESCO, 2011.

GONÇALVES, T. O. Formação e desenvolvimento profissional de formadores de professores: o caso dos professores de matemática da UFPA. Tese de doutorado. Campinas-SP: UNICAMP, 2000.

IMBERNÓN, F. Formação docente e profissional: formar-se para a mudança e a incerteza. 6 ed. São Paulo: Cortez, 2006.

ISAIA, S. M. de A.; MACIEL, A. M. DA R.; BOLZAN, D. P. V. Educação superior: a entrada na docência universitária. In: REUNIÃO ANUAL DA ANPED, 33. 2010, Caxambu. Educação no Brasil: o balanço de uma década. Gt 08 Formação de professores. Caxambu, 2010.

LIBÂNEO, J. C. Adeus professor, adeus professora? São Paulo: Cortez, 1998.

MAUÉS, O. O produtivismo acadêmico e o trabalho docente. In: Universidade e Sociedade. Produção versus produtivismo acadêmico e precarização do trabalho. Ano XVII - n 41 - jan, 2008. p.21-32.

MAUÉS, O. C.; CAMARGO, A. M. M. de. A expansão do ensino superior, políticas de formação docente e atratividade da carreira. Revista Eletrônica de Educação, São Carlos, São Paulo. 8, n. 1, p.77-91, abr. 2014. 
MOROSINI, M. C. Docência universitária e os desafios da realidade nacional. In: MOROSINI, M. C. (org.). Professor do Ensino Superior: identidade, docência e formação. 2 ed. ampl. Brasília: Plano Editora, 2001, p. 15-33.

NÓVOA, A. Formação de professores e profissão docente. In: Nóvoa, A. (Org.) Os professores e sua formação. Lisboa: Dom Quixote, 1995, p.15-33.

PASSOS, L. F. O trabalho do professor formador e o contexto institucional: desafios e contribuições para o debate. Educação e linguagem. Ano 10, n 15 , p.96-116, jan.-jun. 2007.

PIMENTA, S. G.; ANASTASIOU, L. das G. C. Ensino Superior: finalidades. In: PIMENTA, S. G.; ANASTASIOU, L. das G. C. Docência no Ensino Superior. São Paulo, Cortez, 2002, p. 177-200.

PIMENTA, S. G. Professor reflexivo: construindo uma crítica. In: PIMENTA, S. G; GHEDIN, E. (orgs.) Professor reflexivo no Brasil: gênese e crítica de um conceito. São Paulo: Editora Cortez, 2005. p.17-52.

PERRENOUD, P. Formando professores profissionais: quais estratégias? Quais competências? 3. ed. Porto Alegre: Artmed, 2000.

SCHÖN, D. Formar professores como profissionais reflexivos. In: Nóvoa, A. (Org.) Os professores e sua formação. Lisboa: Dom Quixote, 1995, p.77-91.

TARDIF, M. Saberes Docentes e Formação Profissional. $2^{a}$ edição. Petrópolis, Rio de Janeiro: Vozes, 2002.

TEIXEIRA, C. M. D. Docência na educação superior e construção da profissionalidade docente em cursos de licenciatura: continuidades e rupturas. In: REUNIÃO ANUAL DA ANPED, 35. 2012, Porto de Galinhas - PE. Educação, Cultura, Pesquisa e Projetos de Desenvolvimento: o Brasil do século XX. Gt 04 Didática. Porto de Galinhas - PE, 2012.

VAILLANT, D.. Instituições e formadores: definições de uma tipologia. In:

VAILlANT, Denise. Formação de Professores: Estado da Prática. PREAL, 2003.

ZEICHNER, K. Repensando as conexões entre a formação na universidade e as experiências de campo na formação de professores em faculdades e universidades.

Revista Educação, Santa Maria, v. 35, n. 3, p. 479-504, set./dez. 2010.

\section{AUTORES:}

Shirléia dos Santos Peixoto

Mestranda em Políticas Públicas e Direitos Humanos no Núcleo de Estudos de Políticas Públicas em Direitos Humanos (NEPP-DH) da Universidade Federal do Rio de Janeiro (UFRJ). Pedagoga pela Universidade Federal do Rio de Janeiro. Advogada pelo Centro Universitário Augusto Motta (UNISUAM). Pesquisador do Laboratório de Pesquisa em Desigualdade e Diversidade de Corpo, Raça e Gênero (LADECORGEN) da Universidade Federal do Rio de Janeiro (UFRJ). Diretora 
Adjunta de uma escola na Secretaria Municipal de Educação (SME) do Munícipio do Rio de Janeiro.

Fernando Paulo de Lima

Doutor em Educação pela Universidade Federal do Rio de Janeiro (UFRJ); Mestre em Educação pela Universidade Federal de Viçosa (UFV); Licenciado e Bacharel em Educação Física pela Universidade Federal de Viçosa (UFV). Pesquisador do Laboratório de Pesquisa em Desigualdade e Diversidade de Corpo, Raça e Gênero (LADECORGEN) da Universidade Federal do rio de Janeiro (UFRJ). Professor de Educação Física no Ensino Fundamental das séries iniciais na Secretaria Municipal de Educação (SME) do Munícipio do Rio de Janeiro.

José Jairo Vieira

Doutor em Sociologia pelo Instituto Universitário de Pesquisa do Rio de Janeiro (IUPERJ). Mestre em Sociologia do Esporte pela Universidade doestado do Rio de Janeiro (UREJ). Sociólogo pela Universidade Federal do Rio de Janeiro (UFRJ). Licenciado em Educação Física pela Universidade do Estado do Rio de Janeiro (UERJ). Coordenador do Laboratório de Pesquisa em Desigualdade e Diversidade de Corpo, Raça e Gênero (LADECORGEN) da Universidade Federal do Rio de Janeiro (UFRJ). Docente do Programa de Pós-Graduação em Educação (PPGE) e do Programa de Pós-Graduação em História Comparada (PPGHC), ambos da Universidade Federal do Rio de Janeiro (UFRJ)

Recebido em: 2022

Aprovado em: 2022

Publicado em: 2022 